\title{
Heparin Cofactor II Attenuates Vascular Remodeling in Humans and Mice
}

\author{
Ken-ichi Aihara, MD, PhD
}

\begin{abstract}
Heparin cofactor II (HCII), a serine protease inhibitor (serpin), inactivates thrombin action in the subendothelial layer of the vascular wall. Because a congenitally $\mathrm{HCll}$-deficient patient has been shown to have multiple atherosclerotic lesions, it is hypothesized that $\mathrm{HCll}$ plays a pivotal role in the development of vascular remodeling, including atherosclerosis. To clarify this issue, 3 clinical studies concerning plasma $\mathrm{HCll}$ activity and atherosclerosis were carried out, and results demonstrated that a higher incidence of in-stent restenosis after percutaneous coronary intervention, maximum carotid arterial plaque thickness, and prevalence of peripheral arterial disease occurred in subjects with low plasma $\mathrm{HCll}$ activity. Furthermore, $\mathrm{HCll}$-deficient mice were generated by a gene targeting method to determine the mechanism of the vascular protective action of $\mathrm{HCll}$. Because $\mathrm{HCll}^{-/-}$ mice were embryonically lethal, we used $\mathrm{HCll}^{+-}$mice and found that they manifested augmentation of intimal hyperplasia and increased thrombosis after cuff or wire injury to the femoral arteries. $\mathrm{HCll}+/-$ mice with vascular injury showed augmentation of inflammatory cytokines and chemokines and oxidative stress. These abnormal phenotypes of vascular remodeling observed in $\mathrm{HCll}^{+/}$mice were almost restored by human $\mathrm{HCll}$ protein supplementation. $\mathrm{HCll}$ protects against vascular remodeling, including atherosclerosis, in both humans and mice, and plasma $\mathrm{HCll}$ activity might be a predictive biomarker and novel therapeutic target for the prevention of cardiovascular diseases. (Circ J 2010; 74: 1518-1523)
\end{abstract}

Key Words: Heparin cofactor II; Protease-activated receptor-1; Thrombin; Vascular remodeling

$\mathbf{T}$ hrombin is a multipotent serine protease that strongly promotes the coagulation cascade pathway, and thrombin itself is generated at the site of vascular injury. It is well known that thrombin promotes blood clot formation by converting fibrinogen to fibrin; by stimulating platelet aggregation and secretion; and by activating coagulation factors, including factors V, VIII, and XI. Thrombin exerts various biological effects on many cell types, including endothelial cells, vascular smooth muscle cells (VSMCs), monocytes, lymphocytes, and fibroblasts. ${ }^{1}$ Thrombin actions are mediated by protease-activated receptors (PARs), members of a family of G-protein-coupled receptors. Because several studies have demonstrated that upregulation of these receptors is closely associated with the development of vascular lesion formation, including atherosclerosis and coronary artery disease, PARs have been recognized as playing a critical role in the process of cardiovascular remodeling. ${ }^{2}$ The PARs family comprises PAR- 1 to PAR- 4 , and PAR-1 has a central role in thrombin receptor activation-induced vascular remodeling. Because PAR-1 activation accelerates contraction, migration, proliferation, hypertrophy, and production of extracellular matrix in VSMCs and contributes to the development of vascular lesions, such as atherosclerosis, ${ }^{3}$ PAR-1 has been recognized as the principal thrombin receptor in vascular remodeling in humans. In fact, PAR-1-deficient mice manifest partial lethality after birth, and surviving PAR-1-deficient mice show diminished neointimal hyperplasia after arterial injury compared with wild-type mice. ${ }^{4}$ Taking these findings together, thrombin has been shown to have numerous associations not only with thrombotic, but also with non-thrombotic, diseases, including coronary heart disease, stroke, and peripheral arterial disease (PAD)., ${ }^{3,5-7}$ Thus, it is possible that inhibition of thrombin's action will be effective for both the treatment and primary and secondary prevention of cardiovascular diseases. Because heparin cofactor II (HCII) and antithrombin (AT) are endogenous thrombin inhibitors in mammals, this review focuses on the role of HCII in protecting against vascular remodeling and atherosclerosis via its inhibition of thrombin in the vascular wall.

\section{HCIl as a Serine Protease Inhibitor}

Acceleration of thrombin action at sites of vascular wall injury is effectively inactivated by HCII, which in humans is a single-chain glycoprotein containing 480 amino acid residues. In addition to AT, HCII is a serine protease inhibitor (serpin) with a molecular weight of $65.6 \mathrm{kDa}$. HCII is mainly

Received June 21, 2010; accepted June 21, 2010; released online July 17, 2010

Department of Medicine and Bioregulatory Sciences, The University of Tokushima, Graduate School of Health Biosciences, Tokushima, Japan

Mailing address: Ken-ichi Aihara, MD, PhD, Department of Medicine and Bioregulatory Sciences, The University of Tokushima, Graduate

School of Health Biosciences, 3-18-15 Kuramoto-cho, Tokushima 770-8503, Japan. E-mail: aihara@ clin.med.tokushima-u.ac.jp

ISSN-1346-9843 doi:10.1253/circj.CJ-10-0577

All rights are reserved to the Japanese Circulation Society. For permissions, please e-mail: cj@j-circ.or.jp 
A
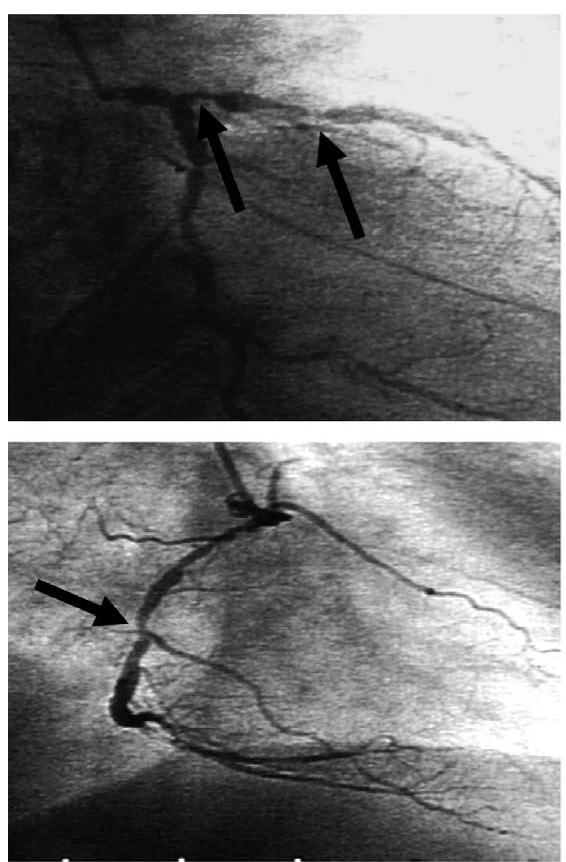

B
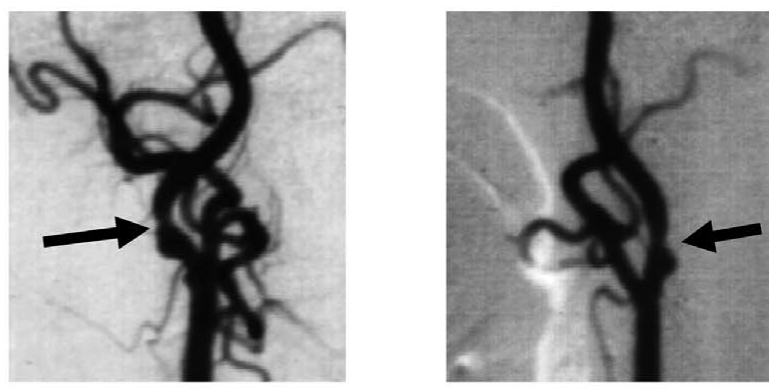

C

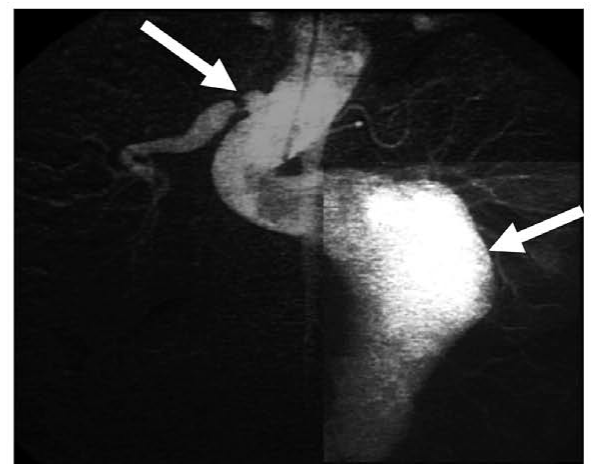

Figure 1. Advanced and multiple atherosclerotic lesions in a woman with congenital heparin cofactor II (HCII) deficiency. (A) Coronary angiography. (Upper) Multiple left anterior descending coronary artery stenoses (arrows). (Lower) Right coronary artery stenosis (arrow). (B) MRI angiography. (Left) Stenosis of the left internal carotid artery (arrow). (Right) Stenosis of the right internal carotid artery right carotid artery (arrow). (C) Abdominal aortography. Upper arrow indicates stenosis of the right renal artery and lower arrow indicates aneurysm of the abdominal aorta. (Reprinted with permission from Aihara et al. ${ }^{22}$ )

synthesized by hepatocytes and secreted into the systemic circulation at a concentration of approximately $1.0 \mu \mathrm{mol} / \mathrm{L},{ }^{8}$ and it is distributed in both the subendothelial vascular wall of atherosclerotic lesions and the walls of normal arteries. In the intravascular lumen, AT inactivates several coagulationrelated proteases, including thrombin, factor $\mathrm{Xa}$, and factor IXa. In the extravascular lumen, HCII counteracts only thrombin without affecting the other proteases involved in the blood coagulation cascade. ${ }^{9}$ Inactivation of thrombin action by HCII is exerted to form a bimolecular complex with dermatan sulfate (DS), a glycosaminoglycan, which is synthesized and secreted by VSMCs and fibroblasts and is deposited in the matrix of the vascular wall, including the intima and media. ${ }^{8,10-15}$ In fact, Rau et al ${ }^{16}$ used immunohistochemistry to demonstrate the colocalization of HCII and thrombin in atherosclerotic plaques of the subendothelial layer of the left anterior descending coronary artery, but AT staining was less intense across all the arterial samples despite having comparable staining intensity to $\mathrm{HCII}$ and thrombin. ${ }^{16}$

\section{Advanced Multiple Atherosclerotic Lesions in a Subject With Congenital HCII Deficiency}

Congenital HCII deficiency is inherited in an autosomal dominant fashion, and several clinical reports have demonstrated that HCII deficiency is associated with venous thrombosis. ${ }^{17-20}$ In addition to AT, HCII has been recognized as a complementary anticoagulant against thrombin-induced thrombosis and hemostasis. A 66-year-old woman was incidentally found to have heterozygous HCII deficiency and we demonstrated that the molecular pathogenesis of reduced plasma HCII activity could be explained by impaired secretion of the mutant HCII molecules because of intracellular degradation. Although she did not suffer from any classical cardiovascular risk factors, except mild essential hypertension, the patient had multiple and advanced atherosclerotic lesions, including multiple coronary artery stenoses, bilateral carotid stenoses, right renal artery stenosis, and an abdominal aortic aneurysm (Figure 1). ${ }^{21,22}$ Because her plasma HCII activity and antigen were remarkably reduced to $41 \%$ and $44 \%$, respectively, it raised the possibility that HCII deficiency is associated with acceleration of the development of atherosclerosis in elderly individuals with endothelial injury.

\section{Inverse Association Between Plasma HCII Activity and Development of Atherosclerosis in Humans \\ Coronary Artery Disease}

We estimated the relationship between plasma HCII activity and coronary artery disease in Japanese elderly subjects ${ }^{23}$ to clarify whether HCII is involved in the development of atherosclerosis. Sequential coronary arteries $(n=166)$ in 134 patients with bare-metal stent implantation were evaluated by angiography before, immediately after, and at 6 months after percutaneous coronary intervention (PCI). This clinical study showed that the high plasma HCII activity group $(\geq 110 \%)$ had a smaller percent diameter stenosis at 6 months after PCI than both the moderate $(\geq 80 \%$ and $<110 \%)$ and low plasma HCII activity groups $(<80 \%)$. In addition, the high plasma HCII activity group demonstrated a lower in-stent 
restenosis rate after PCI than the low plasma HCII activity group. When multivariate analysis was performed, a high level of plasma HCII activity was found to be inversely associated with angiographic restenosis independent of other confounding factors. ${ }^{23}$

Huang et al examined whether plasma HCII activity can predict cardiovascular prognosis in patients with acute myocardial infarction (AMI). ${ }^{24} \mathrm{~A}$ total of 110 consecutive patients (63 \pm 11 years) with AMI were enrolled and divided into 3 groups: high HCII $(>122 \%)$, normal HCII ( $>98 \%$ and $\leq 122 \%$ ), and low HCII ( $\leq 98 \%)$, all of which were followed up for $42 \pm 12$ months. In their study, the high-HCII group had a tendency toward a reduced incidence of major adverse cardiovascular events (MACE), including rehospitalization because of unstable angina, nonfatal myocardial infarction (MI), revascularization with either PCI or coronary artery bypass grafting (CABG), ischemic stroke, and cardiovascular death compared with the other groups. Multivariate regression analysis confirmed that plasma HCII activity was an independent and significant predictor of future MACE.

\section{Carotid Arterial Plaque}

Because the patient with congenital HCII deficiency suffered from bilateral internal carotid arterial stenoses, we hypothesized that HCII also attenuates the development of carotid atherosclerosis and cerebrovascular events. To clarify this hypothesis, we measured plasma HCII activity and carotid arterial intima-media thickness by ultrasonography in 306 Japanese individuals (154 men and 152 women) over 40 years of age (68.9 \pm 11.1 years).$^{25}$ In that study, the maximum carotid plaque thickness was inversely and significantly correlated with plasma HCII activity after adjustment for age and sex. ${ }^{25}$ Furthermore, multiple regression analysis confirmed that plasma HCII activity and high-density lipoprotein cholesterol were independent contributors to the suppression of carotid plaque thickness. Interestingly, we found that the statistical antiatherogenic efficacy of HCII was beyond that of high-density lipoprotein cholesterol. ${ }^{25}$

\section{PAD}

It has been well documented that having PAD is a strong predictor of future cardiovascular and cerebrovascular events such as MI, stroke, and death. ${ }^{26-29}$ Because the vascular risks are already considerably increased in patients with asymptomatic PAD, the clinical importance of early diagnosis during the subclinical stage, as well as subsequent management of vascular risks, is emphasized ${ }^{30}$ Risk factors for the development of peripheral arterial atherosclerosis are almost similar to those for coronary artery disease, such as diabetes mellitus, hyperlipidemia, cigarette smoking, and hypertension. PAD has been also recognized as associated with chronic inflammation and endothelium dysfunction. ${ }^{31}$ Because the endogenous protective factors against progression of PAD are still unknown, we also speculated that HCII plays a protective role against the development of PAD and measured plasma HCII activity and the ankle-brachial pressure index (ABI) in 494 Japanese elderly subjects with cardiovascular risk factors. ${ }^{32}$ Diagnosis of PAD was made by $\mathrm{ABI}<0.9$, and 62 subjects were determined as having PAD. Multivariate logistic regression analysis showed that age, current smoking, and the presence of diabetes mellitus were independently and positively associated with the prevalence of PAD. Conversely, HCII was independently and negatively associated with the prevalence of PAD. ${ }^{32}$ In addition, Schillinger et $\mathrm{al}^{33}$ studied 63 consecutive patients with PAD who underwent femoropopliteal stent implantation after initial failure of plainballoon angioplasty. They measured plasma HCII activity in each patient before stenting and followed them for a median 10 months for the occurrence of the first in-stent restenosis. In that study, cumulative freedom from restenosis at 6 months and at 12 months in the low HCII activity group ( $\leq 100 \%$, lower tertile) was $84 \%$ and $35 \%$, respectively, whereas it was $93 \%$ and $72 \%$ in the high HCII activity group $(>100 \%$, higher tertile). After adjustment for the difference in the implanted stents and other confounding factors, high HCII activity was confirmed to have an antiatherogenic effect against in-stent restenosis in the femoropopliteal artery. Consequently, those results indicate that plasma HCII activity is a predictor not only for the prevalence of PAD but also for restenosis after femoropopliteal stent implantation.

\section{Pathophysiologic Roles of Thrombin and HCII on Endothelial Function}

The endothelium causes relaxation of the underlying vascular smooth muscle by releasing nitric oxide (NO). ${ }^{34,35}$ Vascular endothelial cells respond to shear stress, a fluid mechanical force, and the endothelial cells' responses play an important role in the homeostasis of the circulatory system. ${ }^{36}$ In an in-vitro study, prolonged thrombin incubation was shown to inhibit endothelial NO synthase (eNOS) production in endothelial cells ${ }^{37}$ and increase arginase activity, leading to reduced NO production. On the other hand, high shear stress, which is recognized as a promoting factor of eNOS activation, attenuates PAR-1 expression in endothelial cells. ${ }^{38}$ Clinical evidence has shown that the vasodilator function of the vascular endothelium serves as an indicator of atherosclerotic risk. Recently, measurement of brachial artery flowmediated vasodilation (FMD) has become the most widely used surrogate for evaluating endothelial function, and evidence for the significance of the relationship between FMD and cardiovascular events has been accumulating. ${ }^{39,40}$ Huang et al investigated the pathophysiologic interplay between plasma HCII activity, FMD, and incidence of cardiovascular events. ${ }^{41}$ In their study, Cox regression analyses were conducted for the enrolled subjects (199 patients $63 \pm 14$ years of age), with cardiovascular events being defined as MI, PCI, $\mathrm{CABG}$, ischemic stroke, and peripheral artery revascularization, and endothelial function was assessed using percent FMD (\%FMD). Multivariate analysis showed that age and the level of high-sensitivity C-reactive protein were inversely correlated with \%FMD. On the other hand, it was shown that plasma HCII activity positively correlated with \%FMD. In that study, Kaplan-Meier and Cox regression analyses indicated that low plasma HCII activity was able to predict a high incidence of future cardiovascular events.

\section{In Vitro Studies of HCII Action on Fibroblasts and VSMCs}

In vascular lesions, thrombin accelerates the pro-inflammatory response characterized by increased production of chemokines and cytokines, cell adhesion molecules, enhanced vascular permeability, migration and proliferation of VSMCs, wall thickening, and vasoconstriction. ${ }^{42}$ Hayakawa et al demonstrated that gene transfer-induced expression of HCII inhibited thrombin-induced interleukin-6 (IL-6) release from both fibroblasts and VSMCs. ${ }^{43}$ Because it has been well documented that IL-6, an inflammatory cytokine, has a crucial role in extracellular matrix deposition and reorganization leading to atherosclerosis, ${ }^{44,45}$ their study results suggest that 


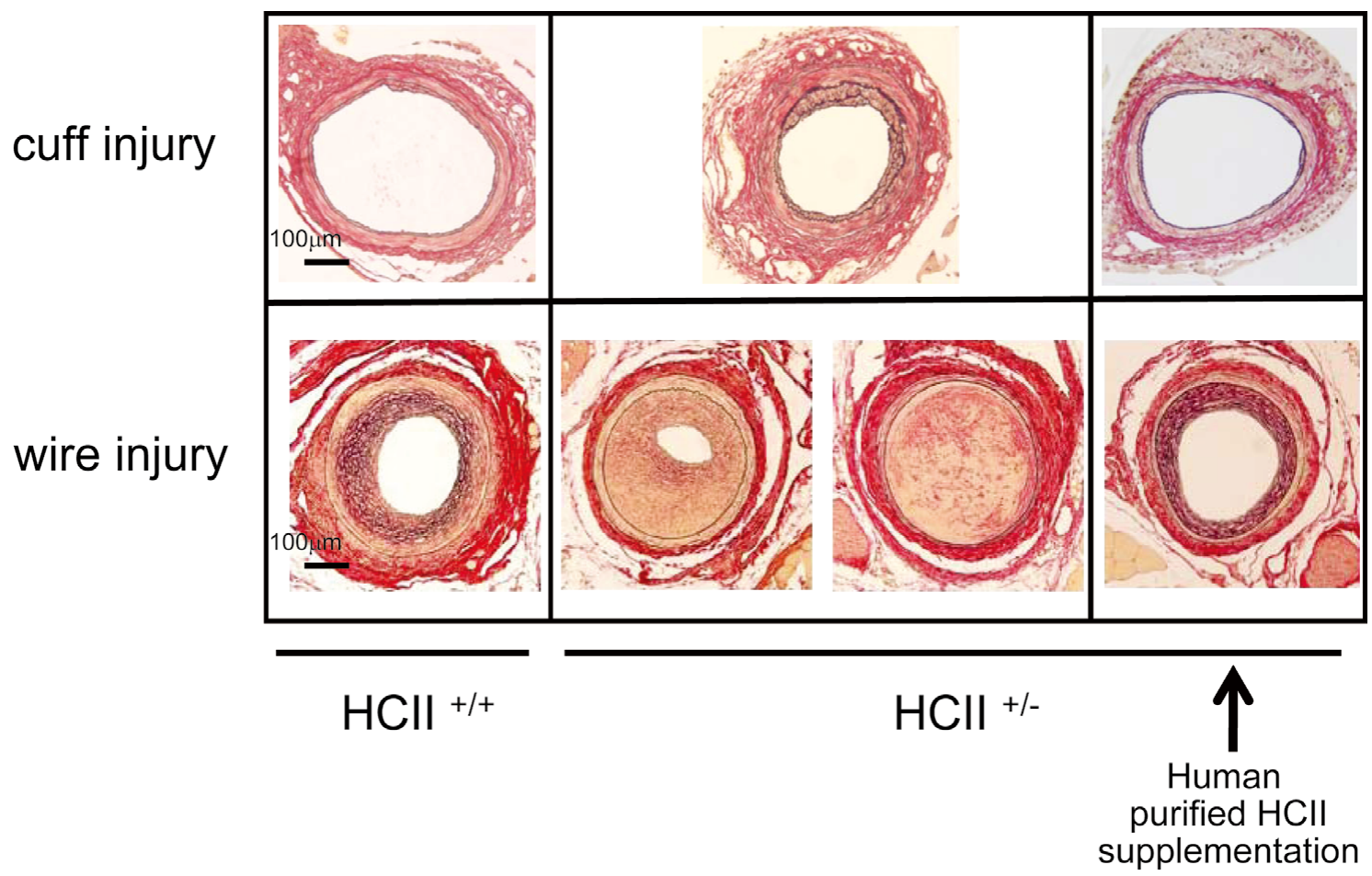

Figure 2. Effect of heparin cofactor II (HCII) deficiency and supplementation with human purified HCll on vascular remodeling in cuff and/or wire-injured femoral arteries of mice. (Upper) Cuff-injured femoral arteries in $\mathrm{HCII}^{+/-}$Tokushima mice show acceleration of neointimal and adventitial hyperplasia. (Lower) Wire-injured femoral arteries in HCll+/- Tokushima mice show prominent neointimal hyperplasia and a high incidence of arterial occlusion because of thrombosis. Those abnormalities were ameliorated by human purified HCll protein supplementation. (Modified from Aihara et al. ${ }^{48}$ )

HCII has protective potency against thrombin-induced vascular remodeling with medial thickening through inhibition of IL-6 production in fibroblasts and VSMCs.

\section{Animal Studies of Vascular Remodeling Using HCII-Deficient Mice}

\section{Embryonic Lethality in Homozygous HCII-Deficient Mice}

Kamp and Ragg demonstrated that the genomic structure of both murine and human HCII consists of 5 exons interrupted by 4 introns. ${ }^{46}$ In 2002, He et al (Washington University) generated and reported on homozygous HCII-deficient mice with deletion of $2 \mathrm{~kb}$ of the murine HCII gene, which encodes the N-terminal half of the protein, including thrombin and DS binding sites. ${ }^{47}$ The $\mathrm{HCII}^{-/-}$offspring were obtained at close to the expected Mendelian frequency by mating male and female $\mathrm{HCII}^{+/-}$mice $\left(\mathrm{HCII}^{+/-} \mathrm{St}\right.$ Louis mice). The HCII-deficient mice appeared identical to their wild-type littermates and did not have spontaneous thrombosis or other baseline hemostatic abnormalities; ${ }^{47}$ however, accelerated thrombotic occlusion of the carotid artery after photochemically induced endothelial cell injury was observed in $\mathrm{HCII}^{-/-}$mice compared with $\mathrm{HCII}^{+/+}$mice.$^{47}$ Enhanced blood coagulation by photochemical injury in the $\mathrm{HCII}^{-/-}$mice was corrected by intravenous infusion of purified human HCII protein. ${ }^{47}$

In 2007, we independently generated, and reported, HCIIdeficient mice by a gene targeting method. Unexpectedly, mice with homozygous deletion of HCII exhibited embryonic lethality even after careful backcrossing for 10 generations with a C57BL/6J strain. ${ }^{48}$ Normal karyotypes by chromosome analysis, and accuracy of homologous recombination of the targeting vector by Southern blotting analysis and FISH analysis were confirmed in our $\mathrm{HCII}^{+/-}$mice $\left(\mathrm{HCII}^{+/-}\right.$ Tokushima). ${ }^{48}$ In addition, we demonstrated the absence of truncated HCII transcripts and noninterference with mRNA levels of neighboring genes around the HCII genome after $\mathrm{HCII}$ targeting vector introduction in $\mathrm{HCII}^{+-}$Tokushima mice. ${ }^{48}$ Because there is a strain difference between embryonic stem cells and the screened genome libraries in $\mathrm{HCII}^{+/-}$ St Louis mice and $\mathrm{HCII}^{+/-}$Tokushima mice, we speculated that the discrepancy in results is related to a minor straindependent difference in genetic background even after backcrossing for 10 generations.

\section{Exaggerated Vascular Remodeling in HCII-Deficient Mice Augmentation of Cuff and Wire Injury-Induced Vascular} Remodeling Histopathologic examinations revealed no morphometric differences between the femoral arteries in $\mathrm{HCII}^{+/+}$and $\mathrm{HCII}^{+/-}$Tokushima mice; however, cuff-injured femoral arteries in the $\mathrm{HCII}^{+-}$mice showed apparently exaggerated intimal and adventitial hyperplasia compared with the $\mathrm{HCII}^{+/+}$mice ${ }^{48}$ (Figure 2). A prominent increase in proliferating cell nuclear antigen and bromodeoxyuridinestained cells suggesting enhanced cellular proliferation were observed in cuff-injured $\mathrm{HCII}^{+-}$Tokushima mice compared with $\mathrm{HCII}^{+/+}$mice. Cuff injury caused robust increases in the expression level of vascular remodeling regulators, including PAR-1, IL-1 $\beta$, IL-6, macrophage chemoattractant protein-1, 


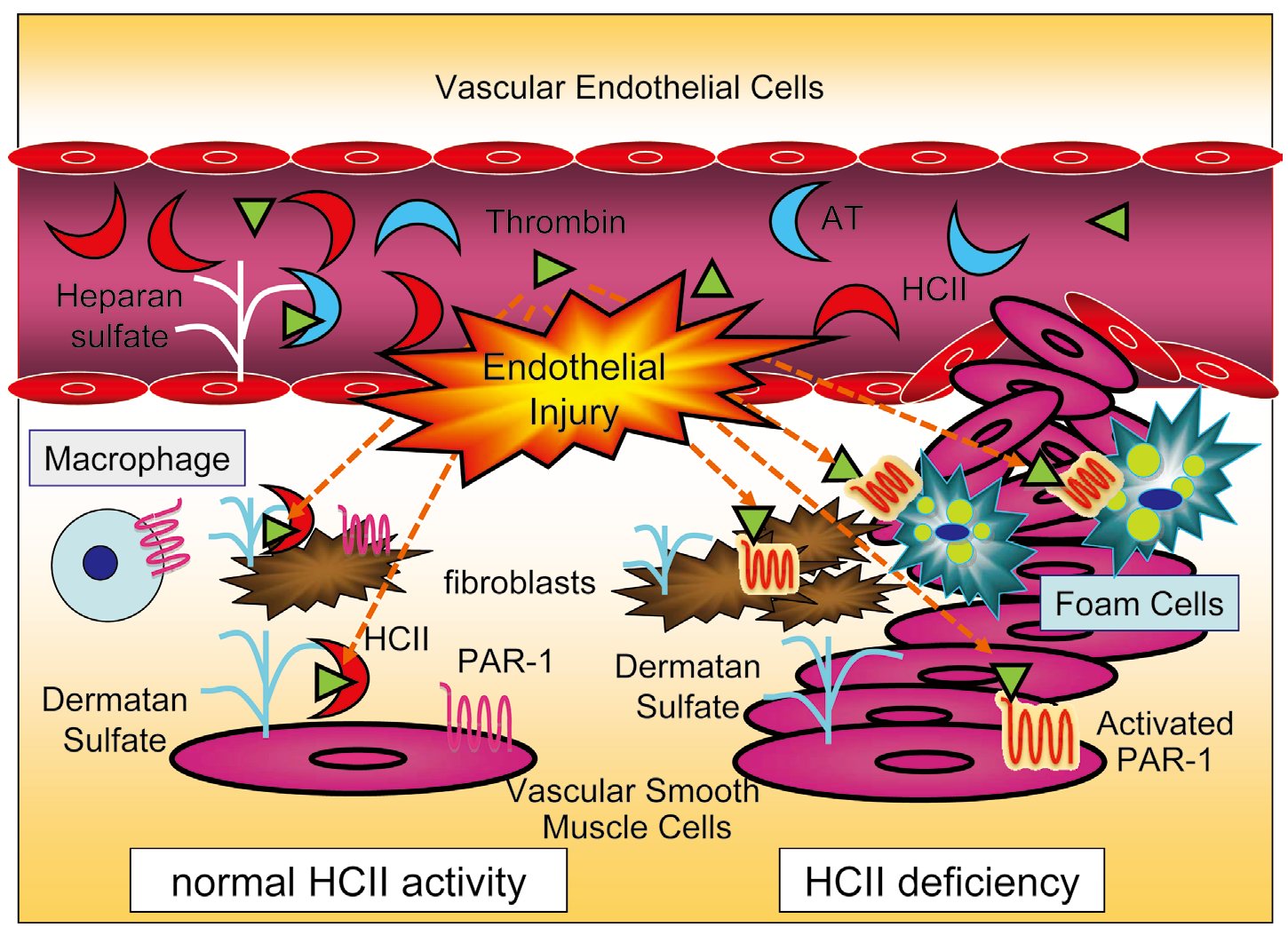

Figure 3. Vascular protective action of heparin cofactor II (HCll) at the site of injured vascular wall. AT, antithrombin; PAR, protease-activated receptor. (Modified from Aihara et al. ${ }^{22}$ )

early growth response gene-1, and Krüppel-like zinc finger transcription factor 5 in $\mathrm{HCII}^{+/-}$Tokushima mice compared with $\mathrm{HCII}^{+/+}$mice. ${ }^{48}$ In addition to the cuff injury model, wire injury promoted much greater neointimal hyperplasia and a higher incidence of occlusive thrombosis in the femoral arteries of $\mathrm{HCII}^{+/-}$Tokushima mice than in those of $\mathrm{HCII}^{+/+}$ mice (Figure 2). Because enhanced platelet aggregation was found in the $\mathrm{HCII}^{+-}$Tokushima mice, reduced HCII activity may cause PAR activation in platelets, leading to increased thrombogenicity. All those aberrant phenotype were ameliorated by administration of human purified HCII protein. ${ }^{48}$ Vicente et al also reported acceleration of neointimal formation in $\mathrm{HCII}^{-/-} \mathrm{St}$ Louis mice and $\mathrm{HCII}^{+/+}$mice 3 weeks after mechanical dilation of the common carotid artery, ${ }^{49}$ which is in agreement with our results.

Advanced Atherosclerosis in HCll-Deficient Mice With Hypercholesterolemia Because hypercholesterolemia is widely recognized as a major risk factor for the development of atherosclerosis and coronary artery disease, we evaluated whether HCII action is involved in the process of lipid disorder-induced atherosclerosis by comparing $\mathrm{HCII}^{+/-}$ (Tokushima) apolipoprotein $\mathrm{E}(\mathrm{ApoE})^{-/-}$mice with $\mathrm{HCII}^{+/+}$ ApoE $^{-/-}$mice. ${ }^{48}$ The atherosclerotic plaque area in the aortic root of the $\mathrm{HCII}^{1-}$ (Tokushima) $\mathrm{ApoE}^{-/-}$mice was much greater than that in the $\mathrm{HCII}^{+/+} \mathrm{ApoE}^{-/-}$mice. In addition, lipid pool accumulation, PAR-1-stained cells, and superoxide production were more prominent in the aortic root of the $\mathrm{HCII}^{+/-}$(Tokushima) $\mathrm{ApoE}^{-/-}$mice than in the $\mathrm{HCII}^{+/+}$ ApoE ${ }^{-/-}$mice. ${ }^{48}$ Vicente et al also generated $\mathrm{HCII}^{-/-}$(St Louis)
$\mathrm{ApoE}^{-/-}$mice and quantified the observed aortic atherosclerosis. ${ }^{49}$ Their double mutant mice manifested greater atherosclerotic plaque areas in the aortic arch compared with that generated by the $\mathrm{HCII}^{+/+} \mathrm{ApoE}^{-/-}$mice. ${ }^{49}$

\section{Summary and Conclusions}

The thrombin-PAR-1 axis activation has a major impact on atherosclerotic development, and is a relatively novel topic. Clinical studies concerning the effects of HCII on atherosclerosis have demonstrated an inverse association between plasma HCII activity and incidence of in-stent restenosis after PCI, carotid atherosclerosis severity, PAD prevalence, endothelial dysfunction, and future cardiovascular events. In experiments using genetically engineered animal models, HCII-deficient mice have shown that HCII counteracts the vascular stress leading to thrombosis and development of vascular remodeling. Figure 3 shows a concept of the antiatherogenic action of HCII. Therefore, HCII might be both a novel predictive marker and a therapeutic target for the treatment of vascular remodeling, including atherosclerosis, in humans and mice.

\section{Acknowledgments}

This work was supported in part by Grants-in-Aid for Scientific Research from the Ministry of Education, Science, Sports and Culture of Japan and a Grant for a Study Group on Aseptic Femoral Neck Necrosis from the Ministry of Health, Labour and Welfare of Japan. 


\section{References}

1. Narayanan S. Multifunctional roles of thrombin. Ann Clin Lab Sci 1999; 29: $275-280$.

2. Derian CK, Damiano BP, D'Andrea MR, Andrade-Gordon P. Thrombin regulation of cell function through protease-activated receptors: Implications for therapeutic intervention. Biochemistry (Mosc) 2002; 67: 56-64.

3. Hirano K, Kanaide H. Role of protease-activated receptors in the vascular system. J Atheroscler Thromb 2003; 10: 211 -225.

4. Cheung WM, D'Andrea MR, Andrade-Gordon P, Damiano BP Altered vascular injury responses in mice deficient in proteaseactivated receptor-1. Arterioscler Thromb Vasc Biol 1999; 19: 3014-3024.

5. Sambrano GR, Weiss EJ, Zheng YW, Huang W, Coughlin SR. Role of thrombin signalling in platelets in haemostasis and thrombosis. Nature 2001; 413: 74-78.

6. Major CD, Santulli RJ, Derian CK, Andrade-Gordon P. Extracellular mediators in atherosclerosis and thrombosis: Lessons from thrombin receptor knockout mice. Arterioscler Thromb Vasc Biol 2003; 23: 931 - 939 .

7. Tschopl M, Tsakiris DA, Marbet GA, Labs KH, Jager K. Role of hemostatic risk factors for restenosis in peripheral arterial occlusive disease after transluminal angioplasty. Arterioscler Thromb Vasc Biol 1997; 17: 3208-3214.

8. Tollefsen DM, Pestka CA, Monafo WJ. Activation of heparin cofactor II by dermatan sulfate. J Biol Chem 1983; 258: 6713-6716.

9. Parker KA, Tollefsen DM. The protease specificity of heparin cofactor II: Inhibition of thrombin generated during coagulation. J Biol Chem 1985; 260: 3501 - 3505

10. Rosenberg LC, Choi HU, Tang LH, Johnson TL, Pal S, Webber C, et al. Isolation of dermatan sulfate proteoglycans from mature bovine articular cartilages. J Biol Chem 1985; 260: 6304-6313.

11. Tollefsen DM. Heparin cofactor II modulates the response to vascular injury. Arterioscler Thromb Vasc Biol 2007; 27: 454-460.

12. Tollefsen DM. Insight into the mechanism of action of heparin cofactor II. Thromb Haemost 1995; 74: 1209-1214.

13. Choi HU, Johnson TL, Pal S, Tang LH, Rosenberg L, Neame PJ. Characterization of the dermatan sulfate proteoglycans, DS-PGI and DS-PGII, from bovine articular cartilage and skin isolated by octylsepharose chromatography. J Biol Chem 1989; 264: 2876-2884.

14. Shirk RA, Parthasarathy N, San Antonio JD, Church FC, Wagner WD. Altered dermatan sulfate structure and reduced heparin cofactor II-stimulating activity of biglycan and decorin from human atherosclerotic plaque. J Biol Chem 2000; 275: 18085-18092.

15. McGuire EA, Tollefsen DM. Activation of heparin cofactor II by fibroblasts and vascular smooth muscle cells. J Biol Chem 1987; 262: $169-175$.

16. Rau JC, Deans C, Hoffman MR, Thomas DB, Malcom GT, Zieske $\mathrm{AW}$, et al. Heparin cofactor II in atherosclerotic lesions from the Pathobiological Determinants of Atherosclerosis in Youth (PDAY) study. Exp Mol Pathol 2009; 87: 178-183.

17. Sie P, Dupouy D, Pichon J, Boneu B. Constitutional heparin cofactor II deficiency associated with recurrent thrombosis. Lancet 1985; 2: 414-416.

18. Tran TH, Marbet GA, Duckert F. Association of hereditary heparin co-factor II deficiency with thrombosis. Lancet 1985; 2: 413-414.

19. Weisdorf DJ, Edson JR. Recurrent venous thrombosis associated with inherited deficiency of heparin cofactor II. Br J Haematol 1991; 77: $125-126$.

20. Blinder MA, Andersson TR, Abildgaard U, Tollefsen DM. Heparin cofactor II Oslo. Mutation of Arg-189 to His decreases the affinity for dermatan sulfate. J Biol Chem 1989; 264: 5128-5133.

21. Kanagawa Y, Shigekiyo T, Aihara K, Akaike M, Azuma H, Matsumoto T. Molecular mechanism of type I congenital heparin cofactor (HC) II deficiency caused by a missense mutation at reactive P2 site: HC II Tokushima. Thromb Haemost 2001; 85: 101-107.

22. Aihara K, Azuma H, Akaike M, Sata M, Matsumoto T. Heparin cofactor II as a novel vascular protective factor against atherosclerosis. J Atheroscler Thromb 2009; 16: 523-531.

23. Takamori N, Azuma H, Kato M, Hashizume S, Aihara K, Akaike $\mathrm{M}$, et al. High plasma heparin cofactor II activity is associated with reduced incidence of in-stent restenosis after percutaneous coronary intervention. Circulation 2004; 109: 481-486.

24. Huang SS, Huang PH, Chen YH, Sung SH, Chiang KH, Chen JW, et al. Plasma heparin cofactor II activity is an independent predictor of future cardiovascular events in patients after acute myocardial infarction. Coron Artery Dis 2008; 19: 597-602.

25. Aihara K, Azuma H, Takamori N, Kanagawa Y, Akaike M, Fujimura M, et al. Heparin cofactor II is a novel protective factor against carotid atherosclerosis in elderly individuals. Circulation 2004; 109: $2761-2765$.

26. McKenna M, Wolfson S, Kuller L. The ratio of ankle and arm arterial pressure as an independent predictor of mortality. Atherosclerosis 1991; 87: 119-128.

27. Criqui MH, Langer RD, Fronek A, Feigelson HS, Klauber MR, McCann TJ, et al. Mortality over a period of 10 years in patients with peripheral arterial disease. $N$ Engl J Med 1992; 326: 381-386.

28. Smith GD, Shipley MJ, Rose G. Intermittent claudication, heart disease risk factors, and mortality: The Whitehall Study. Circulation 1990; 82: $1925-1931$

29. Murabito JM, Evans JC, Larson MG, Nieto K, Levy D, Wilson PW. The ankle-brachial index in the elderly and risk of stroke, coronary disease, and death: The Framingham Study. Arch Intern Med 2003; 163: 1939-1942.

30. Ouriel K. Peripheral arterial disease. Lancet 2001; 358: 1257-1264.

31. Hsieh CJ, Wang PW. Effect of cilostazol treatment on adiponectin and soluble CD40 ligand levels in diabetic patients with peripheral arterial occlusion disease. Circ J 2009; 73: 948-954.

32. Aihara K, Azuma H, Akaike M, Kurobe H, Takamori N, Ikeda Y, et al. Heparin cofactor II is an independent protective factor against peripheral arterial disease in elderly subjects with cardiovascular risk factors. J Atheroscler Thromb 2009; 16: 127-134.

33. Schillinger M, Exner M, Sabeti S, Mlekusch W, Amighi J, Handler $\mathrm{S}$, et al. High plasma heparin cofactor II activity protects from restenosis after femoropopliteal stenting. Thromb Haemost 2004; 92: $1108-1113$.

34. Vanhoutte PM. Endothelial control of vasomotor function: From health to coronary disease. Circ J 2003; 67: 572-575.

35. Vanhoutte PM. Endothelial dysfunction: The first step toward coronary arteriosclerosis. Circ J 2009; 73: 595-601.

36. Ando J, Yamamoto K. Vascular mechanobiology: Endothelial cell responses to fluid shear stress. Circ J 2009; 73: 1983-1992.

37. Eto M, Barandier C, Rathgeb L, Kozai T, Joch H, Yang Z, et al. Thrombin suppresses endothelial nitric oxide synthase and upregulates endothelin-converting enzyme-1 expression by distinct pathways: Role of Rho/ROCK and mitogen-activated protein kinase. Circ Res 2001; 89: 583-590.

38. Nguyen KT, Eskin SG, Patterson C, Runge MS, McIntire LV. Shear stress reduces protease activated receptor-1 expression in human endothelial cells. Ann Biomed Eng 2001; 29: 145-152.

39. Anderson TJ. Prognostic significance of brachial flow-mediated vasodilation. Circulation 2007; 115: 2373-2375.

40. Yeboah J, Crouse JR, Hsu FC, Burke GL, Herrington DM. Brachial flow-mediated dilation predicts incident cardiovascular events in older adults: The Cardiovascular Health Study. Circulation 2007; 115: 2390-2397.

41. Huang PH, Leu HB, Chen JW, Wu TC, Lu TM, Yu-An Ding P, et al. Decreased heparin cofactor II activity is associated with impaired endothelial function determined by brachial ultrasonography and predicts cardiovascular events. Int J Cardiol 2007; 114: 152-158.

42. Borissoff JI, Spronk HM, Heeneman S, ten Cate H. Is thrombin a key player in the 'coagulation-atherogenesis' maze? Cardiovasc Res 2009; 82: $392-403$.

43. Hayakawa Y, Hirashima Y, Yamamoto H, Hayashi N, Kurimoto M, Kuwayama N, et al. Adenovirus-mediated expression of heparin cofactor II inhibits thrombin-induced cellular responses in fibroblasts and vascular smooth muscle cells. Thromb Res 2005; 116: $357-363$.

44. Schieffer B, Selle T, Hilfiker A, Hilfiker-Kleiner D, Grote K, Tietge UJ, et al. Impact of interleukin- 6 on plaque development and morphology in experimental atherosclerosis. Circulation 2004; 110: $3493-3500$.

45. Solis-Herruzo JA, Rippe RA, Schrum LW, de La Torre P, Garcia I, Jeffrey JJ, et al. Interleukin-6 increases rat metalloproteinase-13 gene expression through stimulation of activator protein 1 transcription factor in cultured fibroblasts. J Biol Chem 1999; 274: 3091930926.

46. Kamp PB, Ragg H. Rapid changes in the exon/intron structure of a mammalian thrombin inhibitor gene. Gene 1999; 229: 137-144.

47. He L, Vicente CP, Westrick RJ, Eitzman DT, Tollefsen DM. Heparin cofactor II inhibits arterial thrombosis after endothelial injury. J Clin Invest 2002; 109: 213-219.

48. Aihara K, Azuma H, Akaike M, Ikeda Y, Sata M, Takamori N, et al. Strain-dependent embryonic lethality and exaggerated vascular remodeling in heparin cofactor II-deficient mice. J Clin Invest 2007; 117: $1514-1526$

49. Vicente CP, He L, Tollefsen DM. Accelerated atherogenesis and neointima formation in heparin cofactor II deficient mice. Blood 2007; 110: $4261-4267$. 